\title{
Early Childhood Determinants of Organochlorine Concentrations in School-Aged Children
}

\author{
WILFRIED KARMAUS, E. PAUL DeKONING, HERMANN KRUSE, JUTTA WITTEN, AND \\ NADIA OSIUS \\ Department of Epidemiology, Michigan State University, East Lansing, MI 48823, U.S.A. [W.K., E.P.D.]; \\ Institute of Toxicology, Christian-Albrecht University, D-24105 Kiel, Germany [H.K.]; Ministry of Social \\ Welfare, Department of Health, D-65021 Wiesbaden, Germany [J.W.]; and Institute for Medical \\ Sociology, University Hospital Hamburg, Arbeitsgruppe Epidemiologie, D-20357 \\ Hamburg, Germany [N.O.]
}

\begin{abstract}
ABST
We investigated whether early childhood factors such as
breast-feeding, parity, and smoking contribute to the variation of
organochlorine compounds (OC: dichlorodiphenyldichlo-
roethene, hexachlorobenzene, $\beta$-hexachlorocyclohexane, and the
sum of polychlorinated biphenyls including the congeners 101 ,
118, $138,153,170,180,183$, and 187 ) at approximately 7 y of
age. OC were measured in whole blood of 350 children. Preg-
nancy characteristics and the child's living conditions were
gathered by questionnaires administered to the parents and in-
terviews with the mother. Height and weight were determined
during the medical examination. Exclusion of incomplete data
and nonbiologic children of the mothers yielded a sample of 337
children. We applied regression analysis with indicator variables,
controlling for confounders. No systematic association was de-
tected for birth order or maternal smoking during pregnancy. The
OC concentrations are diluted in children with a higher body
mass index $\left(>18 \mathrm{~kg} / \mathrm{m}^{2}\right.$ ). We found a strong, dose-dependent
relationship between the duration of breast-feeding (none, $1-4$
wk, $5-8$ wk, $9-12 \mathrm{wk},>12$ wk) and the concentration of all five
OCs. Of the potential determinants analyzed, more of the vari-
ance of the OC concentration is accounted for by breast-feeding
\end{abstract}
OCs, such as PCBs, DDE, and $\mathrm{HCB}$, are highly stable, lipophilic compounds that accumulate in tissues that have a high fat content (1). OCs are found in all organs of the body (2). Infant exposures to OCs have been demonstrated to occur through ingestion of contaminated breast milk and in utero (3-11). Owing to their long half-lives, these compounds tend to persist in tissues for many years (12). There is an ongoing discussion of the pros and cons of breast-feeding, especially as it relates to developing nations (13). Breast-feeding is consid-

Received July 21, 2000; accepted November 22, 2000.

Correspondence and reprint requests: Wilfried Karmaus, Dr. med., M.P.H., Department of Epidemiology, Michigan State University, 4660 S. Hagadorn Road, Suite 600, East Lansing, MI 48823, U.S.A.; e-mail: karmaus@pilot.msu.edu

This study was authorized and supported by the Ministry of Environment, Energy, Youth, Family and Health, Hessen, Germany. than by any other variable. Exclusive breast-feeding beyond 12 wk was associated with a doubling of OC whole blood concentration compared with bottle-fed children (dichlorodiphenyldichloroethene, $0.28 \mu \mathrm{g} / \mathrm{L}$ versus $0.55 \mu \mathrm{g} / \mathrm{L} ; \beta$-hexachlorocyclohexane, $0.05 \mu \mathrm{g} / \mathrm{L}$ versus $0.14 \mu \mathrm{g} / \mathrm{L}$; hexachlorobenzene, 0.14 $\mu \mathrm{g} / \mathrm{L}$ versus $0.25 \mu \mathrm{g} / \mathrm{L}$; sum of polychlorinated biphenyls, 0.25 $\mu \mathrm{g} / \mathrm{L}$ versus $0.55 \mu \mathrm{g} / \mathrm{L}$ ). These findings indicate that breastfeeding can lead to an extended duration of increased OC exposure in childhood. (Pediatr Res 50: 331-336, 2001)

$\quad$ Abbreviations
BMI, body mass index
DDE, dichlorodiphenyldichloroethene
ETS, environmental tobacco smoke
HCB, hexachlorobenzene
HCH, hexachlorocyclohexane
PCBs, polychlorinated biphenyls
OC, organochlorine compounds (DDE, HCB, HCH, PCB)
95\% CI, 95\% confidence interval
DL, detection limit

ered to be protective against infections and asthma (14-18) but may contribute to a higher long-lasting exposure to OCs (19-21). Similarly, there has been investigation into whether a greater number of siblings is protective or a risk factor for increased OC exposure from breast-feeding. In general, breast milk had a higher OC concentration in the first lactation, although levels declined with number of children nursed (21-25).

We conducted a large-scale environmental epidemiologic study in the south of the Federal State of Hessen, located in central Germany, in 1994 and 1995. Children were recruited from three regions. One region is situated within a $15-\mathrm{km}$ radius around an industrial waste incinerator and other industries, such as chemical plants in the Rhine Valley, with low mountains on both sides. These industrial sites environmen- 
tally affect several municipalities that lie in the area. The region is also intensively used for the production of vegetables. The second region is $20 \mathrm{~km}$ north of the incinerator area and is also industrial and agricultural. The third region is located in low mountains (approximately $400 \mathrm{~m}$ above sea level).

Other results from this epidemiologic study that focuses on PCBs and thyroid hormones have been published elsewhere (26-28). Our objective in this analysis is to examine, after controlling for potential confounders, the role of early childhood determinants, such as breast-feeding, birth order, and maternal smoking during pregnancy, as predictors of OC concentrations in whole blood of school-aged children. In particular, we investigated DDE, $\mathrm{HCB}, \mathrm{HCH}$, and $\mathrm{PCBs}$, as these were detected in human breast milk and in children in previous studies in Germany $(29,30)$.

\section{METHODS}

Study population. After obtaining permits from the Data Protection Agency of the State of Hamburg, Germany, from the Ministry of Cultural Affairs of Hessen, Germany, and from the local school committees, we identified 1091 second-grade school children (age range, 7-10 y old) in 18 townships. Informed consent was obtained from all participating parents according to the requirements of the Ethical Committee of the Board of Physicians and the Data Protection Agency of the State of Hamburg.

The first survey in 1994 and 1995 consisted of questionnaires for the parents and a medical check-up for the children including measurements of height and weight. Responses from a self-administered questionnaire were available for 671 children. Parents were asked to let their child participate in phlebotomy if passive smoking in the private household did not exceed 10 cigarettes per day in the previous 12 mo.

Questionnaires. Four self-administered questionnaires were used in the survey: one regarding the living conditions of the families, one each for the mother and the father, and one for the data of the child. We asked for the child's age and sex, whether the mother or father were the biologic parents of the child, and for maternal education. Smoking in the child's home in the previous 12 mo was grouped into five categories (no cigarettes, 1-10 cigarettes a day, 11-20 cigarettes a day, 20-30 cigarettes a day, more than 30 cigarettes a day). We asked whether the child was breast-fed, and the duration with and without additional feeding.

We conducted an intensive reproductive interview of the mother, which is based on the interview used in the European Studies on Fertility and Subfecundity (31). We obtained information on the number of pregnancies, the number of births, their dates, and the maternal age. In addition, we asked for information on smoking during pregnancy: "Did you smoke during your pregnancy?" If yes: "How much and how long did you smoke during pregnancy?" The mother was asked the number of cigarettes smoked per day and the beginning and end for three smoking periods (gestational week) with potentially different smoking habits.

One parent accompanied the child in the medical examination. We measured height (in centimeters) and weight (in kilograms) for each child. For blood sampling the Vacutainer system was used, and approximately $25 \mathrm{~mL}$ was drawn.

OCs in blood. OCs including eight PCB congeners (101, $118,138,153,170,180,183,187)$, DDE, HCB, and $\mathrm{HCH}$ were analyzed (in micrograms per liter) in the Institute of Toxicology, University of Kiel, Germany. OCs were analyzed in 5-mL samples of whole blood by high-resolution gas chromatography (model 3400, Varian Company, Darmstadt, Germany) with a ${ }^{63} \mathrm{Ni}$ electron-capture detector. The DL $(2 \times$ the signal to low-noise ratio) was $0.02 \mu \mathrm{g} / \mathrm{L}$ for $\beta$ - and $\gamma-\mathrm{HCH}$, DDE, and each PCB congener, and $0.01 \mu \mathrm{g} / \mathrm{L}$ for HCB and $\alpha-\mathrm{HCH}$. For extraction and cleanup procedures, Florisil and $n$-hexane were used $\left(9 \mathrm{~g}\right.$ Florisil was deactivated with $3 \% \mathrm{H}_{2} \mathrm{O}$ and given in a chromatography column $22 \mathrm{~mm}$ in diameter and $48 \mathrm{~mm}$ in length for elution). The capillary column amounted to $30 \mathrm{~m}$ in length and $0.25 \mathrm{~mm}$ in diameter, containing nitrogen as a carrier gas. The congeners were determined by retention times on the chromatograms and were identified by comparison with known standards. Additionally, reliability was tested with gas chromatography-mass spectroscopy. The laboratory successfully participated in nationwide quality assessments for the determination of the OCs.

Statistical methods. Outcomes of interest were HCB, DDE, PCBs (congeners 101, 118, 138, 153, 170, 180, 183, and 187 and sum of PCBs), and $\alpha-, \beta-$, and $\gamma-\mathrm{HCH}$. The sum of PCBs was calculated as the sum of the sample values of the PCB congeners [sum of seven congeners; one congener (PCB101) was not detected]. For descriptive purposes, the sample values of the OCs were substituted with one half of the DL when values were less than the DL. Because the distributions of the OCs were not normal, the geometric mean, median, and 5th and 95th percentiles are provided.

We analyzed age and sex of the child, BMI, duration of exclusive breast-feeding, maternal smoking during pregnancy, passive smoking of the child, maternal age, and education, as well as birth order and spacing, as potential predictors of OC concentration. BMI, estimated as weight divided by height squared, was grouped into quartiles. Duration of breast-feeding was grouped by 4-wk intervals: none, 1-4 wk, 5-8 wk, 9-12 wk, and $>12$ wk. Any active smoking during pregnancy after 20 wk of gestation was defined as smoking exposure during pregnancy. Passive smoking of the child was grouped into four categories, with the highest category being 20 or more cigarettes per day. Maternal age at birth was grouped into three categories: <26 y, 26-35 y, and 36-45 y. Birth order was grouped into three categories: 1, 2, and 3 or higher. Maternal education was categorized in three groups $(10 \mathrm{y}$ of school and less, more than $10 \mathrm{y}$ of school without university degree, university degree).

Indicator or dummy variables were used to group birth spacing into two categories based on the median spacing of those with a given birth order to denote a given birth order with either a short (less than the median) or long (greater than or equal to the median) birth spacing. The effects were adjusted for potential confounders (age, sex, BMI, passive smoking of the child, breast-feeding, birth order, and birth spacing of the child; maternal cigarette smoking and maternal age). All statistical analyses were performed using SAS software (32). 


\section{RESULTS}

The final study population with phlebotomy is described in Table 1. We obtained blood samples from 350 children and complete OC analyses could be conducted in 343 samples. We could not detect values above the DL $(0.02 \mu \mathrm{g} / \mathrm{L})$ in $97 \%$ of the blood samples for $\alpha-\mathrm{HCH}$; for $\gamma-\mathrm{HCH}, 28 \%$ were below DL. We therefore restricted the analysis to DDE, $\mathrm{HCB}, \beta-\mathrm{HCH}$, and the sum of PCBs, as $<1 \%$ of the sample of children had nondetectable levels of these four variables.

Exclusion of those with incomplete data and the nonbiologic children of the mothers yielded a final sample size of 337 children. Slightly more boys (57\%) than girls (43\%) participated in phlebotomy; and $96 \%$ of the children were between the ages of 7 and 8 y (Table 1). Only $20 \%$ of the children were not exclusively breast-fed whereas $40 \%$ were exclusively breast-fed for $>12 \mathrm{wk}$. Eight percent of the mothers smoked during pregnancy after $20 \mathrm{wk}$ of gestation, and $58.3 \%$ of the mothers were between the ages of 26 and $35 \mathrm{y}$ at birth. Nearly $53 \%$ of the children were first-born, $18.4 \%$ were second-born with a short birth spacing $(<3.08 \mathrm{y})$, and $19.3 \%$ were secondborn with a long birth spacing ( $\geq 3.08 \mathrm{y})$. Less than $10 \%$ of the children were third-born.

Table 2 presents concentrations of $\mathrm{DDE}, \beta-\mathrm{HCH}, \mathrm{HCB}$, and the sum of PCBs in whole blood stratified by breast-feeding,

Table 1. Description of the study population $(n=337)$

\begin{tabular}{|c|c|c|}
\hline Characteristic & $n$ & $\%$ \\
\hline \multicolumn{3}{|l|}{ Age of child (y) } \\
\hline 7 & 152 & 45.1 \\
\hline 8 & 171 & 50.7 \\
\hline 9 & 11 & 3.3 \\
\hline 10 & 3 & 0.9 \\
\hline Male sex & 192 & 57.0 \\
\hline \multicolumn{3}{|l|}{ BMI group $\left(\mathrm{kg} / \mathrm{m}^{2}\right)$} \\
\hline$<15.2$ & 93 & 27.6 \\
\hline $15.2-16.2$ & 84 & 24.9 \\
\hline $16.3-18.0$ & 76 & 22.6 \\
\hline$>18.0$ & 84 & 24.9 \\
\hline \multicolumn{3}{|l|}{ Exclusive breast-feeding (wk) } \\
\hline None & 44 & 19.4 \\
\hline $1-4$ & 17 & 7.5 \\
\hline $4-8$ & 36 & 15.9 \\
\hline $8-12$ & 39 & 17.2 \\
\hline$>12$ & 91 & 40.1 \\
\hline \multicolumn{3}{|c|}{ Smoking during pregnancy after $20 \mathrm{wk}$ of gestation } \\
\hline No & 309 & 91.7 \\
\hline Yes & 28 & 8.3 \\
\hline \multicolumn{3}{|c|}{ Passive smoking of the children (cigs/mo) } \\
\hline 0 & 231 & 68.6 \\
\hline $1-9$ & 80 & 23.7 \\
\hline $10-19$ & 18 & 5.3 \\
\hline 20 or more & 8 & 2.4 \\
\hline \multicolumn{3}{|l|}{ Maternal age at birth (y) } \\
\hline$<26$ & 130 & 38.7 \\
\hline $26-35$ & 196 & 58.3 \\
\hline $36-45$ & 10 & 3.0 \\
\hline \multicolumn{3}{|l|}{ Birth order, birth spacing } \\
\hline 1 & 178 & 52.8 \\
\hline $2,<3.08$ y & 62 & 18.4 \\
\hline $2, \geq 3.08 \mathrm{y}$ & 65 & 19.3 \\
\hline $3+,<4.04 \mathrm{y}$ & 16 & 4.8 \\
\hline $3+, \leq 4.04 \mathrm{y}$ & 16 & 4.8 \\
\hline
\end{tabular}

birth order, maternal smoking during pregnancy after $20 \mathrm{wk}$ of gestation, and BMI. Breast-feeding increases all OC concentrations in whole blood samples of school-aged children. Although there is no pronounced pattern in DDE and $\beta-\mathrm{HCH}$ concentrations with respect to birth order, there is a suggestion of a decrease in the concentration of HCB and sum of PCBs with increasing birth order. In children with a higher BMI, the concentrations of all four OCs are decreased (Table 2). Smoking during pregnancy after $20 \mathrm{wk}$ of gestation is associated with a decrease in OC concentrations (Table 2). Further restricting to those with no breast-feeding $(n=44)$, smoking during pregnancy after $20 \mathrm{wk}$ of gestation is associated with a slight decrease in OC concentrations: in women with maternal smoking during pregnancy after $20 \mathrm{wk}$ of gestation, the geometric mean DDE concentration decreases from $0.22 \mu \mathrm{g} / \mathrm{L}$ to $0.20 \mu \mathrm{g} / \mathrm{L}, \mathrm{HCB}$ decreases from $0.16 \mu \mathrm{g} / \mathrm{L}$ to $0.15 \mu \mathrm{g} / \mathrm{L}$, and the sum of PCBs decreases from $0.36 \mu \mathrm{g} / \mathrm{L}$ to $0.30 \mu \mathrm{g} / \mathrm{L}$. The concentration of $\beta$ - $\mathrm{HCH}$ remains unchanged with maternal smoking during pregnancy for non-breast-fed children.

We additionally stratified the OC concentrations simultaneously by birth order and any breast-feeding (data not shown). Any breast-feeding increases $\mathrm{OC}$ concentrations in whole blood in all cases. In all birth orders, the main difference was between children with and without breast-feeding. The combined stratification does not reveal any combined effect of birth order and breast-feeding. For those who were not breast-fed, the data suggest a slight decrease in the concentrations of sum of PCBs with birth order (birth order $1,0.41 \mu \mathrm{g} / \mathrm{L}$; birth order 2, $0.30 \mu \mathrm{g} / \mathrm{L}$; birth order 3 or higher, $0.33 \mu \mathrm{g} / \mathrm{L}$ ).

Comparing exclusive and total breast-feeding, the effect of the former is stronger, indicating that the association of total breast-feeding and $\mathrm{OC}$ concentrations is diluted by those who did not breast-feed exclusively (data not shown).

To control for any potential confounding effects, linear regression was used to explain the variation of OC concentrations while controlling for all other covariates in the model (Table 3). For the sum of PCB, an increase in age in the children is associated with a decrease in $\mathrm{OC}$ concentration. There is a minimal effect of sex on OC concentration, the sum of PCBs being slightly higher in boys. A BMI $>18.0 \mathrm{~kg} / \mathrm{m}^{2}$ is associated with a decrease in the concentration of DDE ( $p=$ $0.013), \beta-\mathrm{HCH}(p=0.008), \mathrm{HCB}(p=0.044)$, and the sum of PCBs $(p=0.0001)$ when compared with the group with the lowest BMI. OC concentrations in blood increased with increased duration of total breast-feeding when controlling for all other covariates. Compared with non-breast-feeding, all categories of breast-feeding of $5 \mathrm{wk}$ or more are significant in the model $(p<0.05)$. Total breast-feeding for $>12$ wk corresponds to a near doubling of the concentration of DDE, $\beta$ - $\mathrm{HCH}, \mathrm{HCB}$, and the sum of PCBs when compared with no breast-feeding. Exclusive breast-feeding of $>12 \mathrm{wk}$ is associated with a $>200 \%$ increase in OC concentration in the whole blood of school-aged children when compared with children who were not breast-fed at all (DDE, $0.45 \mu \mathrm{g} / \mathrm{L}$ versus 0.22 $\mu \mathrm{g} / \mathrm{L} ; \beta-\mathrm{HCH}, 0.04 \mu \mathrm{g} / \mathrm{L}$ versus $0.1 \mu \mathrm{g} / \mathrm{L} ; \mathrm{HCB}, 0.16 \mu \mathrm{g} / \mathrm{L}$ versus $0.31 \mu \mathrm{g} / \mathrm{L}$; sum of PCB, $0.35 \mu \mathrm{g} / \mathrm{L}$ versus $0.85 \mu \mathrm{g} / \mathrm{L} ; n$ $=226$ for all OCs). For each of these OCs and of the predictors analyzed, more of the variance of the $\mathrm{OC}$ concentration is 
Table 2. OC concentrations in blood $(\mu \mathrm{g} / \mathrm{L})$ stratified by breast-feeding, birth order, and maternal smoking during pregnancy after 20 wk of gestation

\begin{tabular}{|c|c|c|c|c|c|c|c|c|c|c|c|}
\hline \multirow[b]{2}{*}{$\mathrm{OC}$} & \multicolumn{2}{|c|}{$\begin{array}{l}\text { Breast-feeding geometric } \\
\text { mean }(95 \% \mathrm{CI})\end{array}$} & \multicolumn{3}{|c|}{ Birth order geometric mean $(95 \% \mathrm{CI})$} & \multicolumn{2}{|c|}{$\begin{array}{l}\text { Smoking after } 20 \mathrm{wk} \\
\text { geometric mean }(95 \% \\
\mathrm{CI})\end{array}$} & \multicolumn{4}{|c|}{ BMI geometric mean $(95 \% \mathrm{CI})$} \\
\hline & $\begin{array}{c}\text { No } \\
(n=44)\end{array}$ & $\begin{array}{c}\text { Yes } \\
(n=293)\end{array}$ & $\begin{array}{c}1 \\
(n=178)\end{array}$ & $\begin{array}{c}2 \\
(n=127)\end{array}$ & $\begin{array}{l}3 \text { or higher } \\
(n=32)\end{array}$ & $\begin{array}{c}\text { No } \\
(n=309)\end{array}$ & $\begin{array}{c}\text { Yes } \\
(n=28)\end{array}$ & $\begin{array}{c}<15.2 \\
(n=93)\end{array}$ & $\begin{array}{l}15.2-16.2 \\
(n=84)\end{array}$ & $\begin{array}{l}16.3-18.0 \\
(n=76)\end{array}$ & $\begin{array}{c}>18.0 \\
(n=84)\end{array}$ \\
\hline E & $\begin{array}{c}0.22 \\
(0.13-0.37)\end{array}$ & $\begin{array}{c}0.33 \\
(0.13-1.07)\end{array}$ & $\begin{array}{c}0.32 \\
(0.13-0.94)\end{array}$ & $\begin{array}{c}0.29 \\
(0.12-0.96)\end{array}$ & $\begin{array}{c}0.43 \\
.14-3.13)\end{array}$ & $\begin{array}{c}0.32 \\
0.13-0.98)\end{array}$ & $\begin{array}{r}0.2 \\
(0.13-\end{array}$ & $\begin{array}{r}0 \\
(0.16\end{array}$ & $\begin{array}{r}0 . \\
(0.15\end{array}$ & $\begin{array}{c}0.33 \\
0.13-1.28)\end{array}$ & $(0.11$ \\
\hline$\beta$ - $\mathrm{HCH}$ & $\begin{array}{c}0.04 \\
(0.02-0.07)\end{array}$ & $\begin{array}{c}0.07 \\
(0.03-0.31)\end{array}$ & $\begin{array}{c}0.06 \\
(0.02-0.27)\end{array}$ & $\begin{array}{c}0.06 \\
(0.02-0.21)\end{array}$ & $\begin{array}{c}0.09 \\
(0.02-1.79)\end{array}$ & $\begin{array}{c}0.06 \\
(0.02-0.28)\end{array}$ & $\begin{array}{c}0.06 \\
(0.02-0.23)\end{array}$ & $\begin{array}{c}0.07 \\
0.03-0.21)\end{array}$ & $\begin{array}{c}0.07 \\
(0.03-0.20)\end{array}$ & $\begin{array}{c}0.06 \\
(0.02-0.68)\end{array}$ & $\begin{array}{c}0.05 \\
(0.02-0.34)\end{array}$ \\
\hline HCB & $\begin{array}{c}0.16 \\
(0.10-0.25)\end{array}$ & $\begin{array}{c}0.23 \\
(0.11-0.55)\end{array}$ & $\begin{array}{c}0.23 \\
(0.11-0.52)\end{array}$ & $\begin{array}{c}0.22 \\
(0.10-0.55)\end{array}$ & $\begin{array}{c}0.19 \\
(0.11-0.42)\end{array}$ & $\begin{array}{c}0.22 \\
(0.11-0.52)\end{array}$ & $\begin{array}{c}0.18 \\
(0.10-0.57)\end{array}$ & $\begin{array}{c}0.25 \\
(0.14-0.50)\end{array}$ & $\begin{array}{c}0.24 \\
(0.12-0.57)\end{array}$ & $\begin{array}{c}0.22 \\
(0.11-0.53)\end{array}$ & $\begin{array}{c}0.18 \\
(0.10-0.49)\end{array}$ \\
\hline $\begin{array}{c}\text { Sum of } \\
\text { PCB }\end{array}$ & $\begin{array}{c}0.35 \\
(0.18-0.67)\end{array}$ & $\begin{array}{c}0.54 \\
0.20-1.63)\end{array}$ & $\begin{array}{c}0.53 \\
(0.20-1.61)\end{array}$ & $\begin{array}{c}0.49 \\
(0.20-1.40)\end{array}$ & $\begin{array}{c}0.49 \\
(0.17-1.63)\end{array}$ & $\begin{array}{c}0.53 \\
(0.20-1.48)\end{array}$ & $\begin{array}{c}0.37 \\
(0.18-1.65)\end{array}$ & $\begin{array}{c}0.66 \\
(0.33-1.95)\end{array}$ & $\begin{array}{c}0.62 \\
(0.22-1.65)\end{array}$ & $\begin{array}{c}0.50 \\
(0.20-1.48)\end{array}$ & $\begin{array}{c}0.32 \\
(0.15-1.13)\end{array}$ \\
\hline
\end{tabular}

accounted for by exclusive breast-feeding than by any other variable (DDE, $r^{2}=0.151 ; \beta-\mathrm{HCH}, r^{2}=0.162 ; \mathrm{HCB}, r^{2}=$ 0.162 ; sum of PCBs, $r^{2}=0.135$ ). When controlling for all other covariates in the model, there is no effect of maternal smoking on the whole blood concentration of OCs (Table 3). Being a third-born child $>4 \mathrm{y}$ after the birth of the second child is associated with a significant decrease, compared with the first child, for the sum of PCBs and for HCB. For this group, there is, however, an increase in DDE and $\beta-\mathrm{HCH}$.

\section{DISCUSSION}

The data indicate a statistically significant, strong, and doseresponse effect of breast-feeding on OC concentration in whole blood of children at $7 \mathrm{y}$ of age. Specifically, exclusive breastfeeding of $>12$ wk of duration is related to a doubling of the concentration of all measured OCs in whole blood of children at school age. Our data do not support any systematic association between birth order and OC concentration. Similarly, we did not detect an association between maternal smoking during pregnancy and $\mathrm{OC}$ concentration in the whole blood of their offspring.

We had to select a subgroup of the total study population for blood analyses owing to budget constraints. We restricted ourselves to the group having a lower ETS exposure in their homes to reduce the potentially confounding effect of ETS. Parents of 501 children reported an ETS exposure in the children's home in the previous 12 mo of 10 cigarettes per day or fewer. From this group, 317 children participated in the phlebotomy (63\%). Also 25 parents of the subgroup of 162 children with a higher ETS exposure (15.4\%) included their children in the study. The OC concentrations of the children of this group, however, did not differ from the children with lower ETS exposure (Table 3). Complete data were available for 316 children. The subgroup $(n=316)$ with blood samples did not differ from the total group with respect to age and sex.

The exclusion of children with higher ETS exposure at home might affect the OC concentration: smoking is associated with education, which in turn is associated with breast-feeding and therefore subsequent $\mathrm{OC}$ concentrations in children. In our data, smoking exposure during pregnancy decreases with education of the mother. Mothers with basic education (10 y of school and less; $n=108$ ) smoked on average 119.4 cigarettes between gestational week 20 and birth, mothers without a university degree but having more than $10 \mathrm{y}$ of school $(n=$ 145) smoked on average 50.3 cigarettes during the same period, and mothers with a university degree $(n=77)$ smoked on average 10.6 cigarettes in the second half of the pregnancy. Duration of breast-feeding increases with educational status (median, basic education, $6 \mathrm{wk}$; medium education, $12 \mathrm{wk}$ university degree, $24 \mathrm{wk})$. Because of this, the serum OC concentration in children is increased in children with higher educational status of their mothers (e.g. median of the sum of PCBs, university degree, $0.68 \mu \mathrm{g} / \mathrm{L}$; medium education, 0.5 $\mu \mathrm{g} / \mathrm{L}$; basic education, $0.39 \mu \mathrm{g} / \mathrm{L}$ ). Thus, excluding smoking families increases the level of education in our sample, thereby increasing the duration of breast-feeding and thus the $\mathrm{OC}$ concentration later in childhood. Thus, to get unbiased estimates of the predictors, we statistically controlled for the effect of maternal education in the analyses presented in Table 3.

At the time the parents provided individual data on their child and on living conditions, they did not know the individual results of the blood analyses. Thus, the information about contaminants could not have been biased by the selection of the subgroup, or by questionnaire or interview data. The reported OC concentrations were not lipid-based, a potential problem for compounds that are lipophilic in nature. We also determined lipid blood concentrations. However, in our sample of children there is a high correlation between lipid-based and non-lipid-based OC measurements. With the exception of $\mathrm{HCB}$, the correlation between lipid-based and non-lipid-based OC measurements in this population was $\geq 90 \%$; the correlation for HCB was $87.5 \%$ ( $p<0.0001$ for all correlations). Thus, our findings are independent of lipid- or wet weightbased OC determinations. In addition, there was a high correlation between $\mathrm{OC}$ concentrations in blood from a second phlebotomy of the same children 2 y later (DDE, $r=0.86, n$ $=276$; $\mathrm{HCB}, r=0.74, n=270 ; \beta-\mathrm{HCH}, r=0.61, n=270$; sum of PCBs, $r=0.87, n=241 ; p<0.0001$ for all correlations), indicating the persistent nature of these compounds and the stability of the results.

The data indicate a statistically significant and consistent dose-response effect of increased duration of breast-feeding with increased $\mathrm{OC}$ concentration (Table 3). A dose-response association is evident for all four OCs, e.g. total PCB increased 
in the five ordered breast-feeding categories from $0.26 \mu \mathrm{g} / \mathrm{L}$ through $0.27,0.31,0.32$ to $47 \mu \mathrm{g} / \mathrm{L}$ (Table 3). Additionally, the variation in the duration of breast-feeding accounts for approximately $15 \%$ of the variation in OC concentration at the age of about $7 \mathrm{y}$ (Table 3 ). This strong effect of breast-feeding persists when stratified by birth order (data not shown). OCs are lipophilic in nature, traveling with and accumulating in tissues that are high in fat. Breast milk is high in fat, approximately $3.8 \%$ fat by volume (33), and OCs have been shown to be passed via breast milk to nursing children (5-7). Against our assumption (21-25), OC concentrations were not reduced with increasing birth order; we identified a statistically significant increase for being the third child after a spacing of $>4 \mathrm{y}$. That might have been explained, however, with ongoing maternal exposure before each birth that balanced maternal reduction owing to breast-feeding.

We attribute the effect of BMI on the OC levels to a dilution of the initial concentration by increasing body mass. For all four OC, statistical significance is reached at the highest level of BMI.

Contrary to the results of Lackmann et al. (34), we did not find any systematic or statistically significant effect of passive smoking of the children or active smoking of the mothers during pregnancy (after 20 wk of gestation) on OC concentrations in the blood of their children (Table 3). Although our data include exposure caused by breast-feeding, controlling for breast-feeding and other potential confounders causes any apparent effect of smoking during pregnancy on OC concentration to disappear (Table 3). Our inability to detect an effect of smoking on OC concentration is not likely masked by breast-feeding. Indeed, both maternal smoking and $\mathrm{OC}$ exposure have been associated with a decrease in the duration of lactation (35-37). Contrary to the findings by Lackmann et al. (34), Flesch-Janys et al. (38) suggest that, for adults, smoking tends to decrease OC concentrations by inducing an increase in their enzymatic metabolism. Additionally, we restricted the

Table 3. Geometric means of OC concentrations $(\mu \mathrm{g} / \mathrm{L})$ in whole blood in children, controlling for educational status of the mother and all other covariates in the model

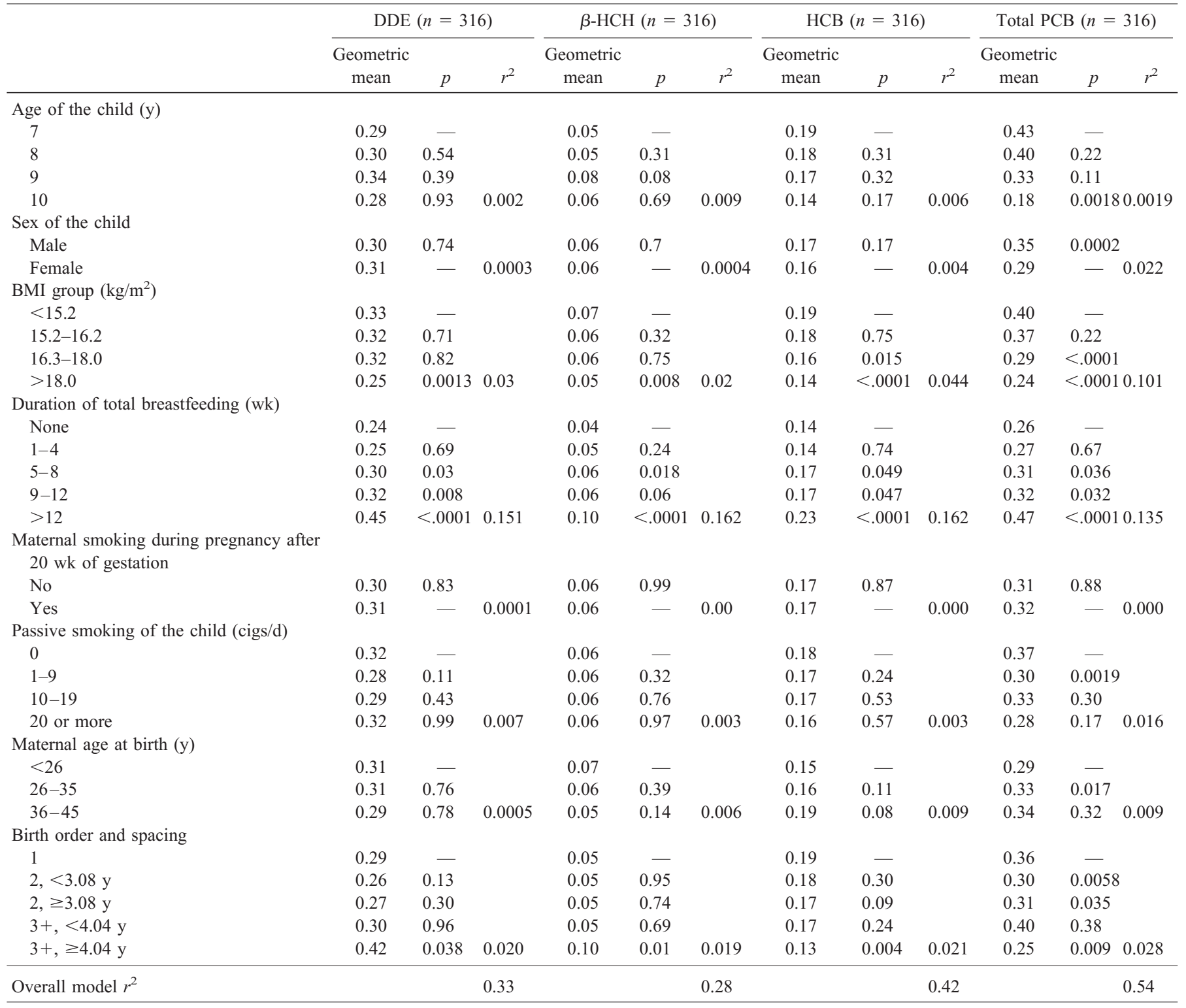


analysis to children who were not breast-fed $(n=44)$. After controlling for confounders, maternal smoking during pregnancy after $20 \mathrm{wk}$ of gestation was associated with no change in OC concentration for $\beta-\mathrm{HCH}(0.02 \mu \mathrm{g} / \mathrm{L})$ and a decrease in $\mathrm{OC}$ concentration for DDE (from 0.13 to $0.11 \mu \mathrm{g} / \mathrm{L}$ ), HCB (from 0.14 to $0.13 \mu \mathrm{g} / \mathrm{L}$ ), and the sum of PCBs (from 0.14 to $0.13 \mu \mathrm{g} / \mathrm{L}$ ); these decreases were not statistically significant. Our data suggest that maternal smoking during pregnancy has no large effect on the amount of OCs transferred to the offspring. However, we cannot exclude that a minor effect of maternal smoking during pregnancy, perhaps present shortly after birth, has already vanished at school age.

In summary, our data indicate that exclusive breast-feeding of $>12$ wk duration is associated with more than a doubling of the whole blood concentration of OCs in children later in life when compared with children who were not breast-fed at all. When controlling for potential confounding variables, no association was detected for birth order or maternal smoking status during pregnancy. Higher BMI showed a diluting effect on the OC blood concentration and needs to be controlled for in future studies.

Acknowledgments The authors thank Linda Fortin for editorial support and the reviewers for thoughtful and excellent suggestions.

\section{REFERENCES}

1. Anonymous 1972 Persistent pesticides and PCBs in the environment. Nature 240:319-320

2. Schecter A, Stanley J, Boggess K, Masuda Y, Mes J, Wolff M, Furst P, Furst C, Wilson-Yang K, Chisholm B 1994 Polychlorinated biphenyl levels in the tissues of exposed and nonexposed humans. Environ Health Perspect 102(suppl 1):149-158

3. Polishuk ZW, Wassermann D, Wassermann M, Cucos S, Ron M 1977 Organochlorine compounds in mother and fetus during labor. Environ Res 13:278-284

4. Rappolt RT, Hale WE 1968 p,p'-DDE and p,p'-DDT residues in human placentas, cords, and adipose tissue. Clin Toxicol 1:57-61

5. Rogan WJ, Gladen BC, McKinney JD, Carreras N, Hardy P, Thullen J, Tingelstad J, Tully M 1986 Polychlorinated biphenyls (PCBs) and dichlorodiphenyl dichloroethene (DDE) in human milk: effects of maternal factors and previous lactation. Am J Public Health $76: 172-177$

6. Jacobson JL, Fein GG, Jacobson SW, Schwartz PM, Dowler JK 1984 The transfer of polychlorinated biphenyls (PCBs) and polybrominated biphenyls (PBBs) across the human placenta and into maternal milk. Am J Public Health 74:378-379

7. Eyster JT, Humphrey HE, Kimbrough RD 1983 Partitioning of polybrominated biphenyls (PBBs) in serum, adipose tissue, breast milk, placenta, cord blood, biliary fluid, and feces. Arch Environ Health 38:47-53

8. Huisman M, Eerenstein SE, Koopman-Esseboom C, Brouwer M, Fidler V, Muskiet FA, Sauer PJ, Boersma ER 1995 Perinatal exposure to polychlorinated biphenyls and dioxins through dietary intake. Chemosphere 31:4273-4287

9. Schlaud M, Seidler A, Salje A, Behrendt W, Schwartz FW, Ende M, Knoll A, Grugel C 1995 Organochlorine residues in human breast milk: analysis through a sentinel practice network. J Epidemiol Community Health 1:17-21

10. Abraham K, Papke O, Gross A, Kordonouri O, Wiegand S, Wahn U, Helge H 1998 Time course of PCDD/PCDF/PCB concentrations in breast-feeding mothers and their infants. Chemosphere 37:1731-1741

11. DeKoning EP, Karmaus W 2000 PCB exposure in utero and via breast milk: a review. J Expo Anal Environ Epidemiol 10:285-293
12. Longnecker MP, Rogan WJ, Lucier G 1997 The human health effects of DDT (dichlorodiphenyltrichloroethane) and PCBs (polychlorinated biphenyls) and an overview of organochlorines in public health. Annu Rev Public Health 18:211-244

13. Brouwer A, Ahlborg UG, van Leeuwen FX, Feeley MM 1998 Report of the WHO working group on the assessment of health risks for human infants from exposure to PCDDs, PCDFs and PCBs. Chemosphere 37:1627-1643

14. Yoon PW, Black RE, Moulton LH, Becker S 1996 Effect of not breastfeeding on the risk of diarrheal and respiratory mortality in children under 2 years of age in Metro Cebu, The Philippines. Am J Epidemiol 143:1142-1148

15. Golding J, Emmett PM, Rogers IS 1997 Eczema, asthma and allergy. Early Hum Devel 49(suppl):S121-S130

16. Silfverdal SA, Bodin L, Hugosson S, Garpenholt O, Werner B, Esbjorner E, Lindquist B, Olcen P 1997 Protective effect of breastfeeding on invasive Haemophilus influenzae infection: a case-control study in Swedish preschool children. Int J Epidemiol 26:443-450

17. Cushing AH, Samet JM, Lambert WE, Skipper BJ, Hunt WC, Young SA, McLaren LC 1998 Breastfeeding reduces risk of respiratory illness in infants. Am J Epidemiol 147:863-870

18. Hanson LA 1998 Breastfeeding provides passive and likely long-lasting active immunity [published erratum appears in Ann Allergy Asthma Immunol 1999;82:478]. Ann Allergy Asthma Immunol 81:523-533(quiz 533-534, 537)

19. Niessen KH, Ramolla J, Binder M, Brugmann G, Hofmann U 1984 Chlorinated hydrocarbons in adipose tissue of infants and toddlers: inventory and studies on their association with intake of mothers' milk. Eur J Pediatr 142:238-244

20. Schwartz PM, Jacobson SW, Fein G, Jacobson JL, Price HA 1983 Lake Michigan fish consumption as a source of polychlorinated biphenyls in human cord serum, maternal serum, and milk. Am J Public Health 73:293-296

21. Bouwman H, Becker PJ, Cooppan RM, Reinecke AJ 1992 Transfer of DDT used in malaria control to infants via breast milk. Bull World Health Organ 70:241-250

22. Vaz R, Slorach SA, Hofvander Y 1993 Organochlorine contaminants in Swedish human milk: studies conducted at the National Food Administration 1981-1990. Food Addit Contam 10:407-418

23. Kostyniak PJ, Stinson C, Greizerstein HB, Vena J, Buck G, Mendola P 1999 Relation of Lake Ontario fish consumption, lifetime lactation, and parity to breast milk polychlorobiphenyl and pesticide concentrations. Environ Res 80:2 Pt 2 S166-S174

24. Hong CS, Xiao J, Casey AC, Bush B, Fitzgerald EF, Hwang SA 1994 Mono-orthoand non-ortho-substituted polychlorinated biphenyls in human milk from Mohawk and control women: effects of maternal factors and previous lactation. Arch Environ Contam Toxicol 27:431-437

25. Schade G, Heinzow B 1998 Organochlorine pesticides and polychlorinated biphenyls in human milk of mothers living in northern Germany: current extent of contamination, time trend from 1986 to 1997 and factors that influence the levels of contamination. Sci Total Environ 215:31-39

26. Osius N, Karmaus W 1998 [Thyroid hormone level in children in the area of a toxic waste incinerator in South Essen]. Gesundheitswesen 60:107-112

27. Osius N, Karmaus W, Kruse H, Witten J 1999 Exposure to polychlorinated biphenyls and levels of thyroid hormones in children. Environ Health Perspect 107:843-849

28. Holdke B, Karmaus W, Kruse H 1998 [Body burden of PCB in whole human blood of 7-10-year-old children in the vicinity of a hazardous waste incinerator]. Gesundheitwesen 60:505-512

29. Institut fuer Wasser- BuLdU 1999 Referenzwerte fuer HCB, beta-HCH, DDT, und $\mathrm{PCB}$ in Frauenmilch. Bundesgesundheitsbl-Gesundheitsforsch-Gesundheitsschutz 42:533-539

30. Ministerium für Arbeit, Gesundheit und Sozialordnung Baden-Württemberg, in Zusammenarbeit mit dem Landesgesundheitsamt Baden-Württemberg und dem Statistischen Landesamt Baden-Württemberg (eds) 1994 Pilotprojekt Beobachtungsgesundheitsämter. Teil 1. Stuttgart:Ministerium für Arbeit, Gesundheit und Sozialordnung Baden-Württemberg

31. Karmaus W, Juul S 1999 Infertility and subfecundity in population-based samples from Denmark, Italy, Poland, and Spain. Eur J Public Health 9:229-235

32. SAS Institute 1999 SAS/STAT Software SAS Institute Inc., Cary, NC, pp 891-996

33. Diem K, ed 1962 Scientific Tables. Geigy Pharmaceuticals Ardsley, New York, p 510

34. Lackmann GM, Angerer J, Tollner U 2000 Parental smoking and neonatal serum levels of polychlorinated biphenyls and hexachlorobenzene. Pediatr Res 47:598-601

35. Gladen BC, Rogan WJ 1995 DDE and shortened duration of lactation in a northern Mexican town. Am J Public Health 85:504-508

36. Sayers G, Thornton L, Corcoran R, Burke M 1995 Influences on breast feeding initiation and duration. Ir J Med Sci 164:281-284

37. Piper S, Parks PL 1996 Predicting the duration of lactation: evidence from a national survey. Birth 23:7-12

38. Flesch-Janys D, Becher H, Gurn P, Jung D, Konietzko J, Manz A, Papke O 1996 Elimination of polychlorinated dibenzo-p-dioxins and dibenzofurans in occupationally exposed persons. J Toxicol Environ Health 47:363-378 